\title{
Características ultraestruturais da mucosa intestinal de bezerros recém- nascidos alimentados na segunda refeição com colostro enriquecido com IGF-I e $\lg ^{1}$
}

\author{
Liris Kindlein², Patricia Pauletti², Adriana Regina Bagaldo², Raul Machado Neto² \\ 1 Trabalho financiado pela FAPESP. \\ 2 Laboratório de Anatomia e Fisiologia Animal, Departamento de Zootecnia, Escola Superior de Agricultura "Luiz de Queiroz", Universidade \\ de São Paulo ESALQ/USP.
}

RESUMO - Objetivou-se estudar os efeitos do fornecimento adicional de colostro de diferentes concentrações de IGF-I e IgG, às 12 horas de vida, sobre as características morfológicas dos enterócitos, bem como a relação entre a quantidade total de IGF-I ingerida e a altura dos microvilos intestinais de bezerros até as 72 horas de vida. Adotou-se o fornecimento prolongado de colostros de diferentes concentrações, incluindo colostro enriquecido com colostro liofilizado. Oitenta e dois bezerros da raça Holandesa receberam, ao nascimento, colostro com concentrações variáveis de $\operatorname{IgG}$ e, às 12 horas de vida, receberam três pools de colostro com densidades variáveis: colostro baixo - IgG e IGF-I inferiores a $30 \mathrm{mg} / \mathrm{mL}$ e $90,65 \mu \mathrm{g} / \mathrm{L}$, respectivamente; alto - IgG e IGF-I superiores a $100 \mathrm{mg} / \mathrm{mL}$ e $344,02 \mu \mathrm{g} / \mathrm{L}$, respectivamente; ou enriquecido de colostro liofilizado - IgG e IGF-I superiores a $120 \mathrm{mg} / \mathrm{mL}$ e 864,68 $\mu \mathrm{g} / \mathrm{L}$, respectivamente. Às 0, 10, 24, 36 e 72 horas de vida, coletaram-se amostras do duodeno, do jejuno (proximal, médio e distal) e do íleo para estudo ultraestrutural. Para determinação da altura dos microvilos, considerou-se o arranjo fatorial $3 \times 3+1$, correspondendo à quantidade total de IGF-I ingerida nas refeições de colostro (0-500, 500-1500, 1500-2500 $\mu \mathrm{g}$ ), três idades de abate (10, 24 e 72 horas de vida) e o grupo controle (nascimento). As características morfológicas dos enterócitos diferiram conforme a idade e as quantidades de IgG e IGF-I disponibilizadas. A quantidade total de IGF-I ingerida teve efeito local positivo sobre a altura dos microvilos intestinais.

Palavras-chave: fator de crescimento semelhante à insulina-I, imunoglobulina, microscopia eletrônica de transmissão, microvilos, morfologia, morfometria

\section{Ultrastructural characteristics of the intestinal mucosa of newborn calves fed in the second meal with colostrum enriched with IGF-I and IgG}

\begin{abstract}
The objective of this study was to evaluate the effects of additional colostrum with different IGF-I and IgG concentrations, at 12 hours of life, on morphological characteristics of enterocytes, as well as the relationship of total amount of IGF-I ingested on the microvillus height of the calves small intestine in the first 72 hours after birth. It was utilized prolonged supply of colostrum with different concentrations, including colostrum enriched with lyophilized colostrum. Eighty two Holstein calves received, at birth, colostrum with different IgG concentrations and, at 12 hours of life, they received three colostrum pools with variable density: low colostrum (IgG and IGF-I inferior to $30 \mathrm{mg} / \mathrm{mL}$ and $90.65 \mu \mathrm{g} / \mathrm{L}$, respectively), high (IgG and IGF-I superior to $100 \mathrm{mg} / \mathrm{mL}$ and $344.02 \mu \mathrm{g} / \mathrm{L}$, respectively), or enriched with lyophilized colostrum (IgG and IGF-I superior to $120 \mathrm{mg} / \mathrm{mL}$ and $864.68 \mu \mathrm{g} / \mathrm{L}$, respectively). At $0,12,24,36$, and 72 hours after birth, duodenum, proximal, medium, and distal jejunum and ileum samples were collected for ultrastructural studies. It was employed a factorial arrangement $3 \times 3+1$, corresponding to the total amount of IGF-I ingested in colostrum meals $(0-500,500-1500,1500-2500 \mu \mathrm{g})$, three slaughter ages (at 10, 24 and 72 hours of life) and control group (at birth) for determination of the microvillus height. Different morphologic characteristics of the enterocytes were observed as consequence of the age, IgG and IGF-I ingested. The total IGF-I amount ingested showed positively local effect on the microvillus height of the intestinal.
\end{abstract}

Key Words: immunoglobulin, insulin like growth factor-I, microvillus, morphology, morphometry, transmission electronic microscopy

\section{Introdução}

O colostro, além de ser a fonte de imunoglobulinas que irão conferir a proteção inicial a bezerros, tem sido relacionado ao desenvolvimento do intestino na fase inicial da vida dos animais (Odle et al., 1996; Blättler et al., 2001). Além dos nutrientes e das imunoglobulinas, o colostro também contém hormônios e fatores de cresci- 
mento como IGF-I, um peptídeo bioativo, considerado potencializador do desenvolvimento gastrintestinal (Bühler et al., 1998; Blum \& Hammon, 1999; MacDonald, 1999; Howarth, 2003).

No início do período pós-natal, durante as primeiras 48 horas de vida, a mucosa intestinal de bezerros apresenta-se altamente permeável a macromoléculas, o que permite a aquisição das imunoglobulinas maternas presentes no colostro (Brambell, 1958; Jeffcott, 1972).

A presença de elevadas concentrações de hormônios e de fatores de crescimento no colostro e no leite regula o crescimento e o desenvolvimento de órgãos do neonato, com maior ênfase ao trato gastrintestinal (Grosvenor et al., 1993; Odle et al., 1996; Shen \& Xu, 1996; Blum \& Hammon, 1999; MacDonald, 1999). Bühler et al. (1998), em pesquisa com bezerros recém-nascidos alimentados com colostro em mais de uma refeição, sugeriram que a suplementação prolongada de colostro influencia a morfologia da mucosa intestinal, pois verificaram aumento significativo no tamanho dos vilos intestinais. Similarmente, Roffler et al. (2003) também verificaram aumento na altura dos vilos intestinais de bezerros neonatos que receberam IGF-I extraído de colostro.

Este trabalho foi realizado com o objetivo de avaliar o efeito do fornecimento adicional de colostro com diferentes concentrações de IGF-I e IgG, às 12 horas de vida, sobre as características morfológicas dos enterócitos, bem como a relação entre a quantidade total de IGF-I fornecida e a altura dos microvilos intestinais de bezerros até as 72 horas de vida.

\section{Material e Métodos}

Utilizaram-se 82 bezerros machos da raça Holandesa. Imediatamente após o nascimento, os animais foram separados das mães, pesados, identificados e receberam a primeira refeição de colostro ( $5 \%$ do peso vivo) com concentração variável de IgG. Às 12 horas de vida, foi fornecida a segunda refeição de colostro com diferentes concentrações de $\operatorname{IgG}$ e, simultaneamente, diferentes concentrações de IGF-I: baixo $=\mathrm{IgG}$ e IGF-I inferiores a $30 \mathrm{mg} / \mathrm{mL}$ e $90,65 \mathrm{mg} / \mathrm{L}$, respectivamente; alto $=$ IgG e IGF-I superiores a $100 \mathrm{mg} / \mathrm{mL}$ e 344,02 mg/L, respectivamente; e enriquecido de colostro liofilizado $=$ IgG e IGF-I superiores a $120 \mathrm{mg} / \mathrm{mL}$ e 864,68 mg/L, respectivamente. Após a ingestão desta refeição, os animais passaram a receber $2 \mathrm{~L}$ de leite integral duas vezes ao dia.

Os pools de colostro foram preparados a partir das primeiras e segundas secreções lácteas de vacas multíparas, coletadas previamente ao experimento. Os pools, depois de centrifugados duas vezes a $12.000 \mathrm{~g}$ por 10 minutos a $4^{\circ} \mathrm{C}$ para retirada parcial da fração lipídica, foram homogeneizados e acondicionados em formas de alumínio de tamanho médio $30 \times 20 \mathrm{~cm}$ e espessura máxima de $1,5 \mathrm{~cm}$ e armazenados a $-20^{\circ} \mathrm{C}$. O colostro congelado foi liofilizado no Instituto Tecnológico de Alimentos. Para a quantificação da fração de IgG do colostro liofilizado, utilizou-se o método de IDR, descrito por Mancini et al. (1965) e modificado por Besser et al. (1985), e, para a quantificação da concentração de IGF-I, empregou-se o ensaio imunoradiométrico pósextração utilizando-se o kit DSL-5600 (Diagnostic Systems Laboratories, Inc.).

A segunda refeição fornecida aos bezerros foi constituída de colostro in natura adicionado ou não de colostro liofilizado (Tabela 1). A concentração de imunoglobulinas do colostro foi estimada pela densidade, obtida utilizando-se um hidrômetro específico (Fleenor \& Stott, 1980). O colostro liofilizado foi adicionado ao colostro até atingir a concentração de IgG desejada, superior a $120 \mathrm{mg} / \mathrm{mL}$. Cada grama do colostro liofilizado adicionado à refeição disponibilizava $560 \mathrm{mg}$ de $\mathrm{IgG}$ e $972 \mu \mathrm{g}$ de IGF-I.

Às $0,10,24,36$ e 72 horas de vida, os bezerros foram pesados, anestesiados e exsangüinados. As cavidades abdominal e torácica foram abertas, ventralmente, desde a região inguinal até o apêndice xifóide. $\mathrm{O}$ trato gastrintestinal

Tabela 1 - Valores médios de IGF-I e IgG das refeições e do colostro liofilizado

\begin{tabular}{|c|c|c|c|c|c|}
\hline \multirow[t]{4}{*}{ Item } & \multicolumn{5}{|c|}{ Tratamento } \\
\hline & \multirow[t]{2}{*}{ 1a refeição } & \multicolumn{4}{|c|}{$1 \underline{a}+2 \underline{a}$ refeição } \\
\hline & & Baixo & Alto & Enriquecido & Liofilizado \\
\hline & \multicolumn{5}{|c|}{ Média $(\mathrm{R} 1+\mathrm{R} 2)^{1} \pm \mathrm{DP}^{2}$} \\
\hline IGF-I $(\mu \mathrm{g})$ & $260,80 \pm 105,49$ & $442,10 \pm 60,90$ & $948,85 \pm 356,38$ & $1.990,16 \pm 286,13$ & $972^{3}$ \\
\hline $\operatorname{IgG}(\mathrm{mg})$ & $76.745 \pm 1.961$ & $131.677 \pm 11.993$ & $216.912 \pm 10.727$ & $423.458 \pm 16.961$ & $560^{4}$ \\
\hline
\end{tabular}

${ }^{1}$ Valores médios encontrados no somatório dos componentes fornecidos nas duas primeiras refeições (nascimento e tratamento).

2 Desvio-padrão da média.

3 Medida em ng/g de liofilizado.

${ }^{4}$ Medida em $\mathrm{mg} / \mathrm{g}$ de liofilizado. 
foi retirado e, por dissecação, separou-se o mesentério aderido ao intestino. Amostras dos segmentos do duodeno, jejuno (proximal, médio e distal) e íleo foram coletadas.

Os segmentos intestinais coletados foram abertos transversalmente, estendidos em placas de Petri e lavados com solução salina $0,9 \%$ a $5^{\circ} \mathrm{C}$. Em seguida, foram pré-fixados por imersão em solução de Karnowsky (2,5\% glutaraldeído, cacodilato de sódio $0,1 \mathrm{M} \mathrm{e} \mathrm{CaCl}_{2} 0,001 \mathrm{M}$ ) por 2 horas. Em seguida, os segmentos intestinais passaram por um processo de pós-fixação em solução de tetróxido de ósmio $1 \%$ em cacodilato de sódio $0,1 \mathrm{M} \mathrm{pH} \mathrm{7,2} \mathrm{por} 2$ horas. Depois de fixados, as secções intestinais foram lavadas em tampão cacodilato de sódio $0,1 \mathrm{M} \mathrm{pH} \mathrm{7,2} \mathrm{e} \mathrm{desidratadas} \mathrm{em} \mathrm{solu-}$ ções de concentrações crescentes ( 30 até $90 \%$ ) de acetona, por dez minutos em cada concentração, finalizando com três lavagens de dez minutos em acetona $100 \%$. Os segmentos foram incluídos em resina Spurr para confecção dos blocos, que, depois de secos, foram seccionados em ultramicrótomo (Reicher, Ultracut E) com navalha de vidro ou de diamante. Utilizando-se telas de cobre, as secções prateadas foram contrastadas com acetato de uranila e citrato de chumbo (Reinholds, 1953).

As amostras destinadas à imunocitoquímica, depois de desidratadas em soluções com concentrações crescentes de etanol, foram embebidas em resina RL White e, por meio de ultramicrótomo, secções douradas foram coletadas em telas de níquel e incubadas sucessivamente em albumina bovina (BSA) por 30 minutos, anti-IgG bovino (Sigma Chemical Co.) diluído 1:1000 em PBS por 10 horas a $4^{\circ} \mathrm{C}$, e proteína A conjugada a ouro (Sigma Chemical Co.) em partículas de $20 \mathrm{~nm}$ na diluição de 1:50 em PBS por 1 hora. A contrastação também foi feita em acetato de uranila e citrato de chumbo. Todas as telas confeccionadas foram examinadas em microscópio eletrônico de transmissão Zeiss EM900 com voltagem de $50 \mathrm{kV}$ e intervalo de aumento de 3.000 até $12.000 \mathrm{X}$, em que as imagens foram selecionadas e captadas. A análise morfométrica foi realizada utilizando-se um sistema de análise de imagens (Axio-Zeiss), em aumento constante (7000X), para comparação dos resultados obtidos. Para cada segmento de cada animal, analisaram-se dez células e fez-se a medição da altura de 30 microvilos por célula (nm).

Para análise da altura dos microvilos, foi utilizado um arranjo fatorial $3 \times 3+1$, considerando a quantidade total de IGF-I ingerida (0-500, 500-1500, 1500-2500 $\mu \mathrm{g})$, as idades de abate (10, 24 e 72 horas) e o grupo controle (nascimento), com média de $7 \pm 1$ animais por grupo.

Amostras dos colostros (primeira refeição, segunda refeição) foram coletadas e mantidas a $-20^{\circ} \mathrm{C}$ para ensaio imunoradiométrico de IGF-I pós-extração utilizando-se o kit DSL-5600 (Diagnostic Systems Laboratories, Inc.) e para quantificação de IgG pelo método de Imunodifusão Radial, descrito por Mancini et al. (1965), modificado por Besser et al. (1985).

\section{Resultados e Discussão}

No estudo da ultraestrutura dos enterócitos de bezerros, observou-se que, ao nascimento, os microvilos do duodeno apresentaram-se desenvolvidos e filamentosos. Esses filamentos, localizados no pólo apical, atravessavam a trama terminal e podiam alcançar o citoplasma. Nesta região, não se observou sinal de invaginações, vesículas ou túbulos. No jejuno, as células intestinais apresentaram-se colunares, com a presença de túbulos e vacúolos vazios na região apical e com o complexo de Golgi na posição subnuclear. No íleo, ao nascimento, as características mais marcantes foram a presença de grandes vacúolos vazios e o complexo de Golgi pouco aparente, com estruturas dispostas na posição supranuclear.

Às 10 e 24 horas após o nascimento, verificou-se a formação de micropinocitose, com invaginações da membrana citoplasmática e formação de vesículas (Figura 1) que dão origem a túbulos que se deslocam para a região basal da célula e, subseqüentemente, se tornam vacúolos (Figura2). Exocitose não foi observada em nenhum segmento intestinal durante o período experimental.

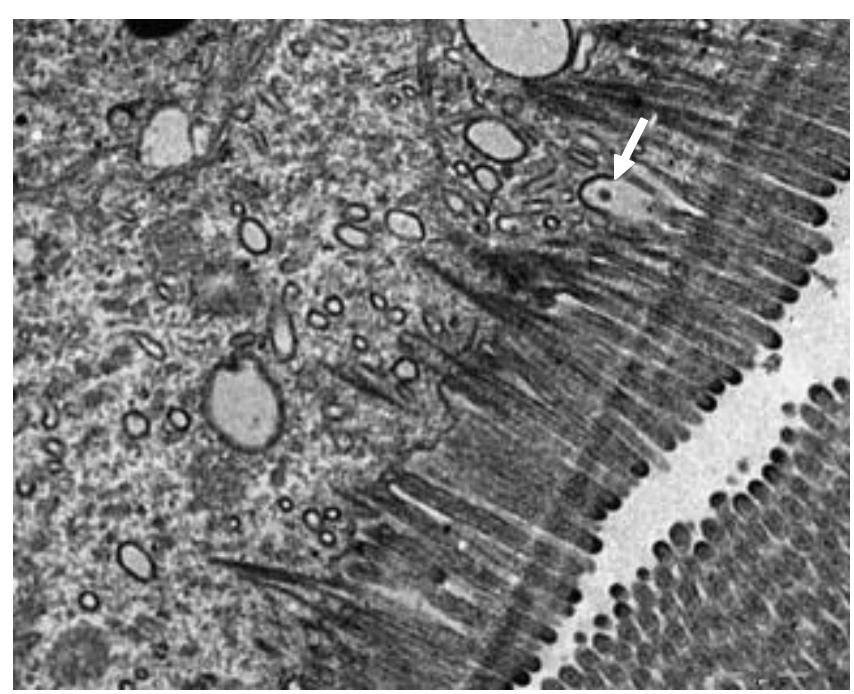

Figura 1 - Enterócito de jejuno distal de bezerro com 24 horas de vida com formação de vesícula (seta), processo de micropinocitose, $\mathrm{X} 7000$. 


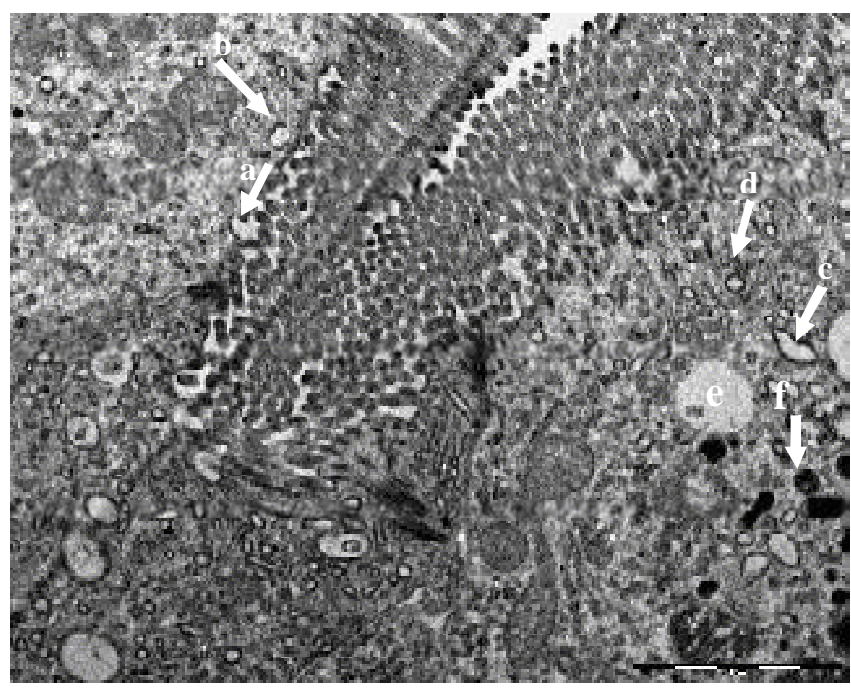

Figura 2 - Enterócito de jejuno distal de bezerro com 24 horas de vida: a - formação de vesícula (seta); b - vesículas na região apical; c - vesículas deslocando-se no citoplasma para a região basal; $d$ - vesículas dilatadas no citoplasma; e - vacúolos maiores e f-estrutura com material elétro-denso.

Nos enterócitos do duodeno de bezerros com 24 horas de vida, foram encontradas pequenas vesículas na região basal da célula. No jejuno, as vesículas e os túbulos localizavam-se em torno do núcleo, situado na região apical do citoplasma. No íleo, os túbulos também apareceram dispostos em torno do núcleo, que se encontrava na região basal da célula.

Às 24 horas, foram encontrados enterócitos com duas características bastante distintas, células com pequenas vesículas e células apresentando túbulos e grandes vacúolos com elevada quantidade de material eletrodenso imunomarcado (Figura 3). A função fisiológica desses vacúolos está relacionada ao armazenamento de IgG proveniente do colostro. De acordo com Smeaton \& SimpsonMorgan (1985), essas duas características dos enterócitos estão relacionadas a diferentes graus de maturação das células. Clarke \& Hardy (1971), em experimento com leitões recém-nascidos, verificaram mudanças no número, no tamanho e na localização de vacúolos do intestino delgado após declínio da passagem de macromoléculas da célula para a circulação, indicativos de uma segunda geração de células incapaz de internalizar macromoléculas presentes no lume. Hardy et al. (1971), em estudo de enterócitos de leitões do nascimento até 3 semanas de idade, encontraram até 28 horas de vida vacúolos relativamente grandes e claros com material eletrodenso. Após esta idade, verificaram que estas estruturas apresentavam-se em diferentes fases de regressão. Segundo Staley (1969a), a ultraestrutura das células intestinais de

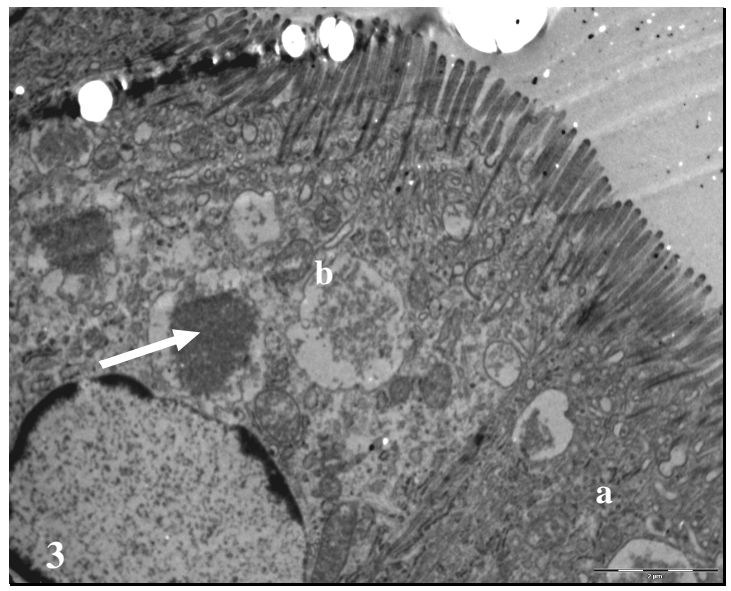

Figura 3 - Citoplasma apical de enterócito, às 24 horas, com presença de vacúolos com material elétrodenso (seta), apresentando célula com pequenos vacúolos (a) e célula com grandes vacúolos (b), X4400.

leitões sofre transição nas primeiras 36 horas após o nascimento.

Neste estudo, a presença de vacúolos grandes e claros sugere envelhecimento celular decorrente de uma possível lise das membranas vesiculares, provavelmente relacionada à liberação de $\mathrm{IgG}$ presente nas membranas. Com a idade, o número de células com grandes vacúolos diminuiu, uma vez que estas células foram substituídas por enterócitos que continham pequenas vesículas, o que está de acordo com a teoria da substituição celular de Oudar et al. (1976) e Smeaton \& Simpson-Morgan (1985).

Às 24 e 72 horas de vida, verificou-se grande quantidade de células caliciformes (Figura 4) no duodeno, assim como no jejuno (proximal, médio e distal) também foram observadas estruturas com material eletrodenso (Figura 2), que provavelmente correspondem a lisossomos com IgG, e a presença de atividade proteolítica intracelular.

Às 24 horas, as células jejunais permaneceram colunares com microvilos desenvolvidos e os complexos de Golgi localizados nas regiões subnucleares ou distribuídos em volta do núcleo. Os núcleos apresentavam canais citoplasmáticos entre as dobras da membrana nuclear rodeados de mitocôndrias e restritos principalmente às porções basais da célula. Também neste período foi verificada grande quantidade de pequenas vesículas situadas adjacentemente às membranas basais das células. Essas células também possuíam vesículas tubulares apicais bem desenvolvidas (Figura 1) e o complexo tubular formado encontrava-se 
na região apical do citoplasma e na trama terminal (Figura 2), comprovando diferentes graus de invaginação na superfície da membrana. Às 36 horas, esse complexo não estava mais presente na trama terminal, apenas nas regiões apical e lateral do citoplasma dos enterócitos (Figura 5), sugerindoo término da permeabilidade a macromoléculas. Na região

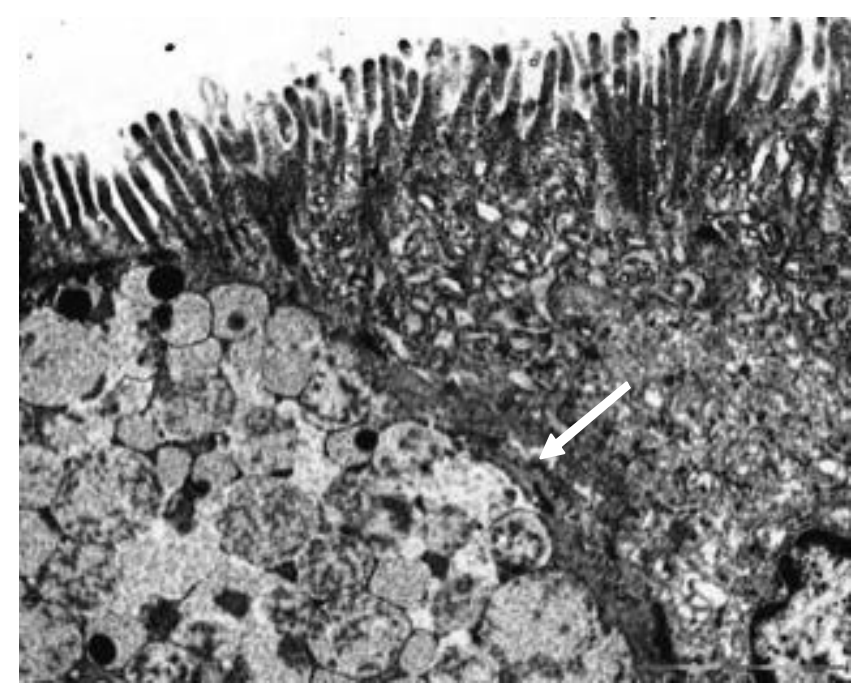

Figura 4 - Citoplasma apical de enterócito duodenal de bezerro com 24 horas de vida sem a presença de vesículas e túbulos. Células caliciformes com grânulos mucinógenos (seta), dispostas entre células epiteliais do intestino, X4400.

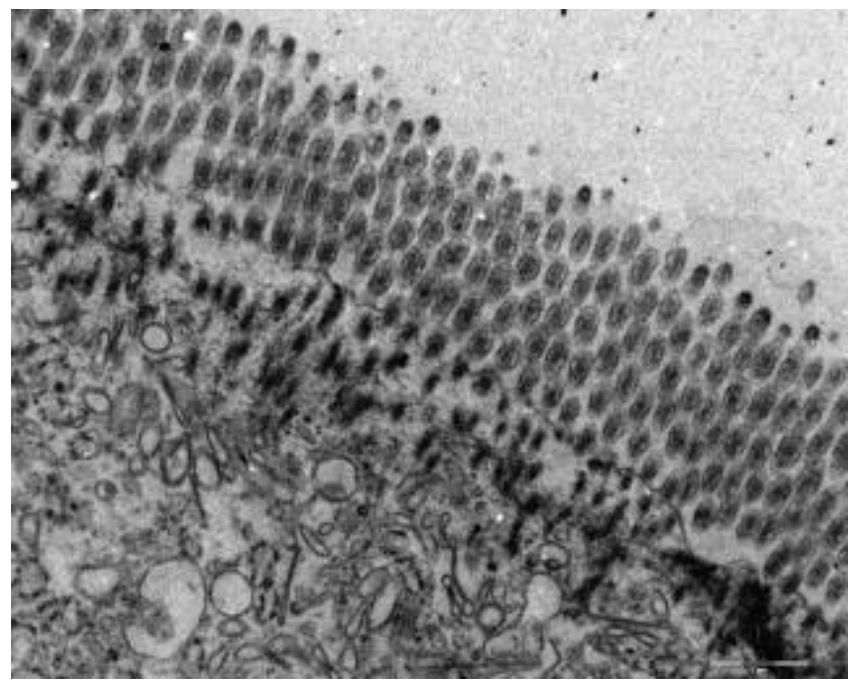

Figura 5 - Jejuno médio de bezerro com 36 horas de vida com túbulos dilatados situados na região apical do citoplasma (seta) e ausentes na trama terminal, X7000. supranuclear, encontrou-se grande quantidade de vacúolos com material eletrodenso no interior, conectados diretamente aos túbulos (Figura 6).

No grupo que recebeu colostro adicionado de colostro liofilizado, às 24 e 36 horas de vida, observou-se maior incidência de estruturas com material eletrodenso, provavelmente lisossomos. As observações deste estudo podem ser explicadas ao mecanismo proposto por Fahey \& Robinson (1963), citados por Junghans (1997), que sugeriram a existência de um limite para internalização e de proteção das IgG pelos enterócitos. Baixa disponibilidade de IgG resulta em absorção completa desta macromolécula, sem incorrer degradação nos lisossomos, enquanto, com alta disponibilidade, uma fração é catabolisada e degradada pelos lisossomos dos enterócitos.

Nas células ileais, similarmente às jejunais, foram observados microvilos curtos com grandes vacúolos supranucleares, chegando a ocupar, às 36 horas, dois terços das células apicais e estendendo-se até próximo datrama terminal. Neste segmento, os vacúolos apresentaram-se maiores em comparação às outras regiões, característica também encontrada por Staley et al. (1972) e Stair et al. (1973), que a relacionaram ao mecanismo de internalização por micropinocitose. Às 72 horas, também no íleo, não foi mais encontrada presença de túbulos, vesículas ou vacúolos, características de células mais maduras. Jockims et al. (1994) observaram que o processo de internalização da IgG nos enterócitos aumenta do duodeno para o íleo, condição observada também neste estudo, no qual a vacuolação ocorrida nos enterócitos foi crescente da região cranial para caudal do intestino delgado.

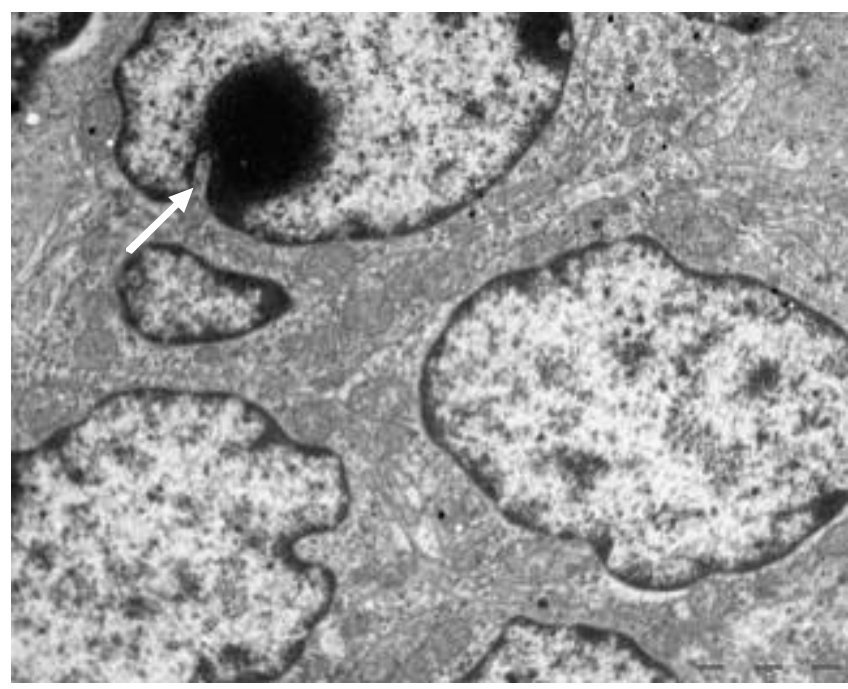

Figura 6 - Jejuno proximal de bezerro com 24 horas de vida com grande quantidade de vacúolos com material elétrodenso (seta) situados na região supranuclear, X3000.

(C) 2008 Sociedade Brasileira de Zootecnia 
Tabela 2 - Altura dos microvilos dos segmentos do intestino delgado dos bezerros

\begin{tabular}{|c|c|c|c|c|c|}
\hline Segmento & Duodeno & Jejuno proximal & Jejuno médio & Jejuno distal & Íleo \\
\hline Abate (h) & \multicolumn{5}{|c|}{ Média \pm DP (nm) } \\
\hline \multirow[t]{2}{*}{0} & $1.010,32 \pm 32,65 \mathrm{a}$ & $1.332,13 \pm 83,35 \mathrm{a}$ & $920,88 \pm 46,30 \mathrm{a}$ & $1034,17 \pm 156,06 a$ & $645,87 \pm 32,69 a$ \\
\hline & \multicolumn{5}{|c|}{ Ingestão de 0-500 $\mu \mathrm{g}$ de IGF-I } \\
\hline 24 & $1.260,39 \pm 88,52 \mathrm{Ab}$ & $1.191,47 \pm 69,85 \mathrm{abA}$ & $1.062,80 \pm 59,64 \mathrm{bA}$ & $760,15 \pm 39,17 \mathrm{bA}$ & $909,77 \pm 42,45 \mathrm{bA}$ \\
\hline \multirow[t]{2}{*}{72} & $991,35 \pm 43,84 \mathrm{Aa}$ & $1.149,02 \pm 66,87 \mathrm{bA}$ & $863,60 \pm 41,52 \mathrm{aA}$ & $611,95 \pm 27,86 \mathrm{cA}$ & $551,75 \pm 42,72 \mathrm{cA}$ \\
\hline & \multicolumn{5}{|c|}{ Ingestão de 500-1500 $\mu \mathrm{g}$ de IGF-I } \\
\hline 24 & $888,57 \pm 93,46 \mathrm{Bb}$ & $1.581,20 \pm 112,40 \mathrm{bB}$ & $1.555,30 \pm 77,27 \mathrm{bB}$ & $973,96 \pm 63,62 \mathrm{aB}$ & $780,89 \pm 48,76 \mathrm{bB}$ \\
\hline \multirow[t]{2}{*}{72} & $1.111,48 \pm 78,76 \mathrm{Ba}$ & $1.323,87 \pm 58,83 \mathrm{ab}$ & $900,95 \pm 42,96 \mathrm{aAB}$ & $643,06 \pm 30,09 \mathrm{bA}$ & $585,35 \pm 45,10 \mathrm{aA}$ \\
\hline & \multicolumn{5}{|c|}{ Ingestão de $1500-2500 \mu \mathrm{g}$ de IGF-I } \\
\hline 24 & $892,15 \pm 95,21 \mathrm{Bb}$ & $1.796,11 \pm 115,02 \mathrm{bC}$ & $1.081,86 \pm 64,60 \mathrm{bA}$ & $849,60 \pm 98,67 \mathrm{aAB}$ & $1.123,58 \pm 111,21 b C$ \\
\hline 72 & $1.138,67 \pm 108,72 \mathrm{Ba}$ & $1.358,21 \pm 97,12 \mathrm{aB}$ & $957,27 \pm 60,64 \mathrm{aB}$ & $670,06 \pm 31,77 \mathrm{bA}$ & $601,88 \pm 37,63 \mathrm{aA}$ \\
\hline
\end{tabular}

Médias seguidas de letras minúsculas diferentes na mesma coluna comparando diferentes ingestões diferem $(P<0,05)$ pelo teste Tukey. Médias seguidas de letras maiúsculas diferentes na mesma coluna comparando diferentes idades diferem $(P<0,05)$ pelo teste Tukey.

$\mathrm{Na}$ análise dos valores médios da altura $(\mathrm{nm})$ dos microvilos intestinais (Tabela 2), verificou-se interação entre a quantidade total de IGF-I ingerida $(\mu \mathrm{g})$ e os segmentos dentro de cada período ( $\mathrm{P}<0,0001)$.

Às 72 horas de vida, os animais que ingeriram 500 a $1.500 \mu \mathrm{g}$ e 1500 a $2500 \mu \mathrm{g}$ de IGF-I apresentaram maiores valores de altura dos microvilos do duodeno em comparação àqueles que receberam $0 \mathrm{a} 500 \mu \mathrm{g}$. Do mesmo modo, às 72 horas, no jejuno proximal, os animais que ingeriram 500 a 1.500 e 1.500 a $2.500 \mu \mathrm{g}$ de IGF-I apresentaram maiores valores de altura de microvilos em comparação aos que in geriram baixa quantidade (0 e $500 \mu \mathrm{g})$. Também nesta idade, analisando os valores da altura dos microvilos do jejuno médio, verificou-se diferença significativa entre os animais que receberam entre 0 e $500 \mu \mathrm{g}$ de IGF-I (863,60 \pm $41,52 \mathrm{~nm})$ e aqueles que receberam mais que $1.500 \mu \mathrm{g}(957,27$ $\pm 60,64 \mathrm{~nm}$ ). Entretanto, no jejuno distal e no íleo, não foram encontradas diferenças significativas.

Os dados do comportamento da altura dos microvilos do nascimento às 72 horas indicam que a massa total de IGF-Iingerida influenciou a altura dos microvilos dos segmentos mais craniais (duodeno, jejuno proximal e jejuno médio), o que sugere efeito local positivo sobre o desenvolvimento celular.

\section{Conclusões}

As características morfológicas dos enterócitos diferiram conforme a idade e as quantidades de IgG e IGF-I disponibilizadas. Quantidades elevadas de IGF-I ingerida tiveram efeito local positivo sobre a altura dos microvilos intestinais.

\section{Literatura Citada}

BESSER, T.E.; GARMEDIA, A.E.; McGUIRE, T.C. Effects of colostral immunoglobulin $\mathrm{G}_{1}$ and immunoglobulin $M$ concentrations on immunoglobulin absorption in calves. Journal of Dairy Science, v.68, n.8, p.2033-2037, 1985.

BLÄTTLER, U.; HAMMON, H.M.; MOREL, C. et al. Feeding colostrum, its composition and feeding variably modify proliferation and morphology of the intestine and digestive enzyme activities of neonatal calves. Journal of Nutrition, v.131, n.4, p.1256-1263, 2001.

BLUM, J.W.; HAMMON, H. Endocrine and metabolic aspects in milk-fed calves. Domestic Animal Endocrinology, v.17, n.2/3, p.219-230, 1999.

BRAMBELL, F.W.R. The passive immunity of the young mammal. Biological Reviews, v.33, n.4, p.488-531, 1958.

BÜHLER, C.; HAMMON, H.; ROSSI, G.L. et al. Small intestinal morphology in eight-day-old calves fed colostrum for different durations or only milk replacer and treated with long- $\mathrm{R}_{3}$ insulin-like growth factor-I and growth hormone. Journal of Animal Science, v.76, n.3, p.758-765, 1998.

CLARKE, R.M.; HARDY, R.N. Histological changes in the small intestine of the young pig and their relation to macromolecular uptake. Journal of Anatomy, v.108, Pt.1, p.63-77, 1971.

FAHEY, J.L.; ROBINSON, A.G. Factors controlling serum $\gamma$-globulin concentration. Journal of Experimental Medicine, v.118, n.5, p.845-868, 1963.

FLEENOR, W.A.; STOTT, G.H. Hydrometer test for estimation of immunoglobulin concentration in bovine colostrum. Journal of Dairy Science, v.63, n.6, p.973-977, 1980.

HARDY, R.N.; HOCKADAY, A.R.; TAPP, R.L. Observations on the structure of the small intestine in foetal, neo-natal and suckling pigs. Philosophical Transactios of the Royal Society of London, Series B., v.259, n.834, p.517-531, 1971.

HOWARTH, G.S. Insulin-like growth factors-I and the gastrointestinal system: Therapeutic indications and safety implications. Journal of Nutrition, v.133, n.7, p.2109-2112, 2003.

JEFFCOTT, L.B. Passive immunity and its transfer with special reference to the horse. Biological Reviews, v.47, n.4, p.439464, 1972.

JOCHIMS, K.; KAUP, F.J.; DROMMER, W. Immunoelectron microscopical demonstration of the absorption of colostral 
IgG by small intestinal enterocytes in newborn rats. Research in Veterinary Science, v.57, n.2, p.146-151, 1994.

JUNGHANS, R.P. Finnally! The Brambell receptor (FcRB). Immunologic Research, v.16, n.1, p.29-57, 1997.

MacDONALD, R.S. The role of insulin-like growth factors in small intestinal cell growth and development. Hormone Metabolic Research, v.31, n.2/3, p.103-113, 1999.

ODLE, J.; ZIJLSTRA, R.T.; DONOVAN, S.M. Intestinal effects of milk borne growth factors in neonates of agricultural importance. Journal of Animal Science, v.74, n.10, p.25092522, 1996.

OUDAR, J.; LARVOR, P.; DARDILLAT, J. et al. L'immunité d'origine colostrale chez le veau. Revue de Médicine Vetérinaire, v.127, p.1309-1346, 1976.

REINHOLD, J.G. Total protein, albumin and globulin. In: REINER, M. (Ed.) Standard methods of clinical chemistry. New York: Academic Press, 1953. v.1, p.88.
ROFFLER, B.; FAH, A.; SAUTER, S.N. et al. Intestinal morphology, epithelial cell proliferation, and absorptive capacity in neonatal calves fed milk-born insulin-like growth factor-I or a colostrum extract. Journal of Dairy Science, v.86, n.5, p.1797-1806, 2003.

SMEATON, T.C.; SIMPSON-MORGAN, M.W. Epithelial cell renewal and antibody transfer in the intestine of the fetal and neonatal lamb. Australian Journal of Experimental Biology and Medical Science, v.63, n.1, p.41-51, 1985.

STAIR, E.L.; MEBUS, C.A.; TWIEHAUS, M.J. et al. Neonatal calf diarrhea. Veterinary Pathology, v.10, p.155-170, 1973.

STALEY, T.E. Fine structure of duodenal absorptive cells in the newborn pig before and after feeding colostrum. American Journal of Veterinary Research, v.30, n.4, p.567-581, 1969a.

STALEY, T.E.; CORLEY, L.D.; BUSH, L.J. et al. The ultrastructure of neonatal calf intestine and absorption of heterologous proteins. Anatomical Records, v.172, n.3, p.559-580, 1972. 